\title{
An Assessment of Solid Waste Management Practices and Awareness in School of Science Gujarat University
}

\author{
Prachi H. Talsania ${ }^{1}$, Dr. Nainesh R. Modi ${ }^{2}$ \\ Department of Botany, Bioinformatics and climate change and impacts management, \\ School of science, Gujarat University. \\ ${ }^{I}$ Email id: - prachitalsania@gmail.com
}

\begin{abstract}
Solid waste is useless and unwanted material, which generated by human activities in residential, industrial, institutional and commercial areas. The Gujarat University is the largest university in the state catering to the needs of higher education of more than four lakh students scattered over 286 colleges, 22 recognized institutions and 24 approved institutions. Increasing solid waste is gigantic problem in the university. In this paper, solid waste management with awareness in the school of science at Gujarat University was discuss in detail. Questionnaire was prepared to gather information about waste generation. Data have collected by personal interview at different departments at Gujarat University. In that questionnaire, basic question about waste generation, waste collection and awareness question was included. Major waste generated in the school of science is paper waste, which is $37 \%$. Plastic waste $26 \%$ and other waste like glass, metal, garden waste, wood etc. In addition, majority of the students are very serious about the waste management problems, poor waste management practices, and lack of legislation. At institutional level, majoring population is young crowd at University. They are very much concern about waste management. Hence, awareness campaign give very positive impact on them. These can easiest adapt to new ideas. Therefore, we all can live in to the pure, healthy and pollution free environment.
\end{abstract}

Index Terms- solid waste management, awareness, environment, questionnaire, society, campaign.

\section{INTRODUCTION}

With rapid of urbanisation in urban populations, there was a drastic change in not only amount of solid waste but also composition with having new material. The type of decision making that leads to sufficient solid waste management claims a sound understanding of the composition and the process that determine the generation of waste (Acurio et al.,1997).

In general, a $1 \%$ increase in population is associated with a $1.04 \%$ increase in the solid waste generation, and a $1 \%$ increase in per capita income is associated with a $0.34 \%$ increase in total solid waste generation (Wang et al., 2011). Domestic and industrial solid waste is causing environmental pollution and has become a gigantic problem for humanity. If this solution not managed in the proper manner within time, then it would lead to extremely calamities consequences on global level (Bambhulkar A. V., 2011). Poorly collected or improper disposal of solid waste have detrimental impact on environment, public health, as well as climate change (El-fedal et al., 1997).

Open dumps of municipal solid waste are creating serious threat to the environment. Strong wind and storm are spreading dust and ooze from the open dumps to the nearby area. Adjacent areas to the dumpsite has affected due to odour emitting from these dumps (Ejaz, N. et al, 2010).

Anthropogenic methane gas emission from landfill sites is main source of methane emission, which is impacts on climate change. Methane gas is 23 times more potent at trapping heat in the atmosphere rather than any GHG gas emission. Low birth rate, cancer, congenital malformations, neurological disease nausea and vomiting and mercury toxicity from eating fish with high level of mercury observed disease, which caused because of unmanaged solid waste (Singh, P., 2013)

Universities has considered similar to small towns because to their large size, population, and the various complex activities taking place on campuses (H.M. Alshuwaikhat, I. Abubakar, 2008). As such, they not only need to maintain an appropriate physical infrastructure, they require similar utilities to small towns, including accommodation, transport, retail, and waste management.

Universities are key sites of tertiary learning and research, major employers, economic actors and providers of culture, recreational and infrastructure resources (Lambert R., 2003) and they have corporeal capacity to catalyse and promote societal transition towards sustainable solid waste management (Stephens et al., 2008). Integrated solid waste management practices are one of the greatest challenges for university's sustainable development (C. Armijo de Vega et al., 2008). Universities generates thousands of tonnes of solid waste like paper, plastic, glass, food waste etc.

Colleges and universities have the moral and ethical onus to act responsibly towards the environment. The young generation should be leaders in movement for environmental protection. Broadly, it has expected that universities would drive the efforts towards accredited solid waste management. Current study focus on status of solid waste generation at school of science Gujarat University. For proper 


\section{Available online at $w w w . i j r a t . o r g$}

integrated solid waste management at Gujarat University characteristic of solid waste, composition of waste, amount of waste is essential tool for assessment.

There are more than 16 major institutes in the Gujarat University like school of science, school of commerce, school of languages and so on. Daily solid waste generation from the university campus is approx. $\quad 100 \mathrm{Kg} /$ day. University have 76-80 housekeeping sweepers. Some are contact based and others are without contact.

In university, door-to-door collection method has used for waste collection. In waste collection, mixed waste collected from the campus. No segregation done into the campus. Waste collection van from Ahmedabad Municipal Corporation collected mixed waste from the big containers situated at the outer part of Gujarat University gate.

The waste generated by Gujarat University is not properly segregated. There are certain standard municipality methodologies are available to segregation of waste. There are two dumping site in the campus, one is at near health centre and another is at near library which is closed now. The various departments and various sections of the University, waste is merged at this site and then given it to the AMC waste collection van. The cleaning process had done on the daily basis to the University.

The present study have performed in autumn season. During autumn season, dry leaves are abundant in the campus. The fraction of dry waste is high in to the autumn season. Approximately 40 bins of $20 \mathrm{kgs}$ been collected from campus. From out of, approx. 15 to 20 bines are from school of science. Daily roughly 100 drums of waste been generated from University Campus. Total area of university of 217 acre. Total waste has collection bin in to the campus is 80 to 100 of 100 liters. No treatment or recycling process done in to the campus. In normal season 60 to 80 bins waste generated from the campus.

The current study was accomplish only at school of science, Gujarat University. In school of science department of botany bioinformatics and climate change impact management, department of chemistry, department of physics, department of statistic and maths, department of microbiology etc. all the samples were analysed at department of Botany.

\section{METHODOLOGY}

\subsection{Research methodology}

Sub-headings should be typeset in boldface and capitalize the first letter of the first word only. Section number to be in boldface roman. Secondary data collected through questionnaire. The questionnaire divided into three phases. Phase one includes questionnaire date, interviewers name, interviewer's occupation, contact details, Name of the department, Total staff of the department, Total cleaning staff, Total numbers of laboratories and total numbers of class rooms included in phase 1.
In phase two, identification of waste generation in University at individual level is covered. Paper, plastic \& rubber, glass and ceramic, garden waste, wood, food waste, metal etc. Positive or negative behaviour of waste is mention here. Then after different functions that carried out by the department like, street sweeping, grass cutting etc. with their remarks are included. Moreover, a set of questions are below.

\begin{tabular}{|l|l|l|}
\hline Question & Yes & No \\
\hline Do you separate different type of waste? & & \\
\hline $\begin{array}{l}\text { Would you do so if your collection } \\
\text { service provider tells you? }\end{array}$ & & \\
\hline $\begin{array}{l}\text { Are there any large bins in your } \\
\text { department? }\end{array}$ & & \\
\hline $\begin{array}{l}\text { Do you have regular garbage collection } \\
\text { in your department? }\end{array}$ & & \\
\hline $\begin{array}{l}\text { How often do you use the collection } \\
\text { services? }\end{array}$ & & \\
\hline
\end{tabular}

Table 1:- Different questions from questionnaire

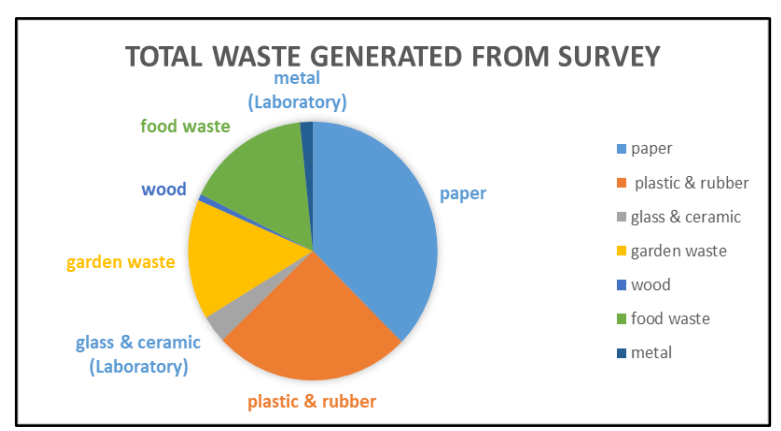

In phase three includes, awareness and current practices in the university and at individual level is covered. Different problems related to the awareness in current practices happening in university at individual level like, lack of financial resources for solid waste management, lack of equipment, lack of legislation etc.

\section{RESULTS AND DISCUSSION}

Results from the survey stated that out of $200,79 \%$ people disposed generated waste to the nearby container, from the result of table 1 , people disposed waste in to open spaces is $14 \%, 5 \%$ people disposed waste in to near campus. $45.5 \%$ people segregate the waste and $54.5 \%$ people does not segregate the waste. $75 \%$ people said that there are regular collection of waste in their department and $25 \%$ said no. $91.5 \%$ population used collection services.

Five major problems with graphs mentioned here in the graph. In university, from the figure 1, highest generated waste is paper waste $(37 \%)$, plastic and ceramic waste $(26 \%)$, garden waste $(15 \%)$, food waste $(16 \%)$, glass waste $(3 \%)$, metal waste $(2 \%)$, and wood waste $(1 \%)$. From the figure 2, majority of the public will say that inadequate services given by the sanitation staff is serious problem. Very less percent 


\section{Available online at www.ijrat.org}

public feels that it is no problem for the university solid waste management.

Figure 3 showed, the percentage of people would feel that the sanitation staff does not given good quality of services. This problem is serious problem as shown in figure 3. Lack of trained persons is very serious problem, which has showed in figure 4. Figure 5 stated lack of legislation in the university is very serious problem. From figure 6, poor public cooperation is serious problem. Because if the public will not cooperate to the sanitation staff and the university, the integrated solid waste management in the university is not possible.

Therefore, overall people are aware about problems related to the solid waste. Figure 7 proved that majority of people feel the problem very serious or serious and others felt there are no problems in the university related to the solid waste.

Figure-1: Total waste generation from survey

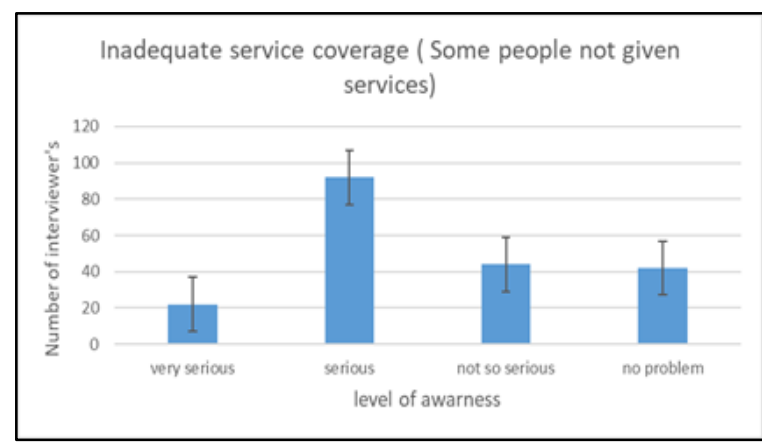

Figure-2: Graph of inadequate service coverage Figure-3: Lack of service quality

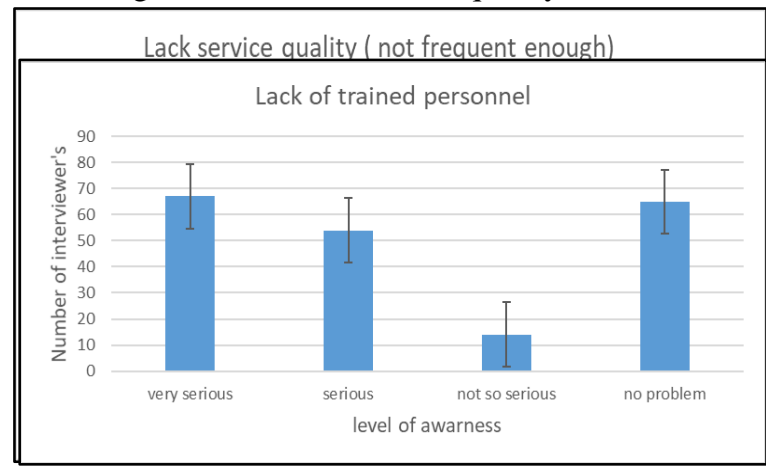

Figure-4: Lack of trained personnel

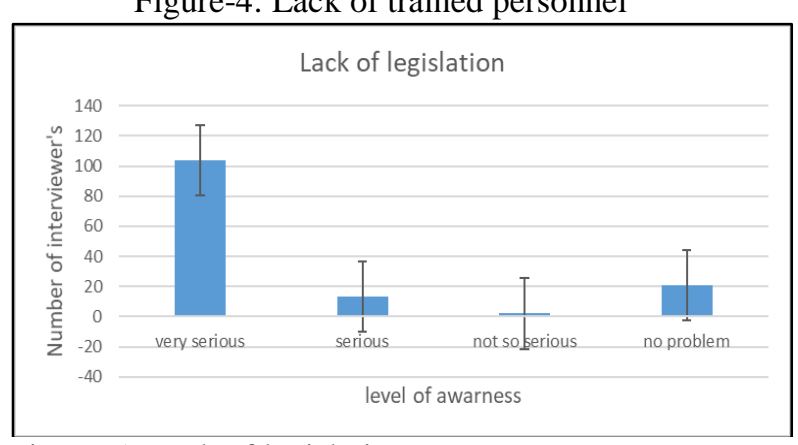

Figure-5: Lack of legislation
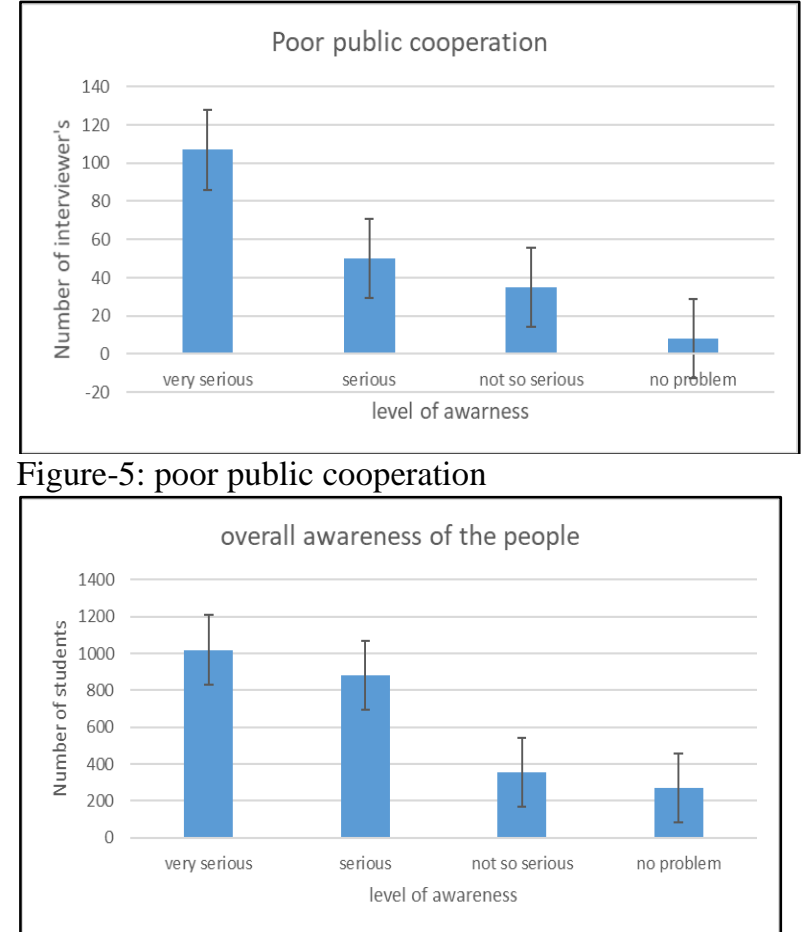

Figure-7: Overall awareness of the people

\section{CONCLUSION}

In university, highest number of people are very serious about the problems associated with waste collection. People are very much aware about waste management. The highest generated waste is paper and plastic. Therefore, the university have to take steps towards the recycling or reuse this waste.

\section{SUGGESTIONS}

Every department has installed paper-shredding machine for recycling and reuse of paper. Like department of Botany are used waste plastic bottle for vertical gardening. Like that all department should reuse waste plastic bottles. . Food waste and garden waste can be put in to the biogas plant and get manure and methane gas. Biodegradable waste can give to the company who manufactured RDF pallets for fuel. Shredded paper can sold to the company who make paper. Metal waste, which is mostly aluminium foil is also recyclable. In university awareness, campaign and training programs to department staffs along with students have carried out to regular intervals.

\section{Acknowledgments}

The author is extremely grateful to Dr. Dhara Bhavsar for her guidance and support. I would also like to thank Mr, Pathik Bhatt, friends, teaching and nonteaching staff of school of science, Gujarat University for their constant support during my research work.

\section{REFERENCES}

[1] Acurio, G., Rossin, A., Teixeira, P. F., \& Zepeda, F. (1997). Situation of the municipal solid waste management in Latin America and the Caribbean. BID No. ENV, 97, 107. 
[2] Alshuwaikhat, H. M., \& Abubakar, I. (2008). An integrated approach to achieving campus sustainability: assessment of the current campus environmental management practices. Journal of cleaner production, 16(16), 1777-1785.

[3] Bhambulkar, A. V. (2011). Municipal solid waste collection routes optimized with arc gis network analyst. International Journal of Advanced Engineering Sciences And Technologies, Vol, (11), 202-207.

[4] de Vega, C. A., Benítez, S. O., \& Barreto, M. E. R. (2008). Solid waste characterization and recycling potential for a university campus. Waste management, 28, S21-S26.

[5] Ejaz, N., Akhtar, N., Hashmi, H., \& Naeem, U. A. (2010). Environmental impacts of improper solid waste management in developing countries: A case study of Rawalpindi city. The sustainable world, 142, 379-387.

[6] El-Fadel, M., Findikakis, A. N., \& Leckie, J. O. (1997). Environmental impacts of solid waste landfilling. Journal of environmental management, 50(1), 1-25.

[7] Lambert, R. (2003). Lambert review of businessuniversity collaboration. University of Illinois at Urbana-Champaign's Academy for Entrepreneurial Leadership Historical Research Reference in Entrepreneurship.

[8] Singh, P. (2013). Impact of Solid Waste on Human Health: A Case Study of Varanasi City. Month.

[9] Stephens, J. C., Hernandez, M. E., Román, M., Graham, A. C., \& Scholz, R. W. (2008). Higher education as a change agent for sustainability in different cultures and contexts. International journal of sustainability in higher education, 9(3), 317-338.

[10] Wang, H., He, J., Kim, Y., \& Kamata, T. (2011). Municipal solid waste management in small towns: An economic analysis conducted in Yunnan, China. The World Bank. 